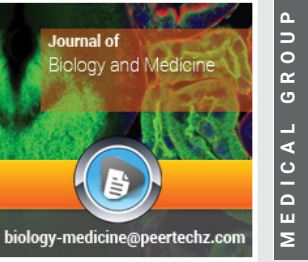

\section{Health-related quality of life of stroke patients before and after intervention: Systematic} review

\author{
Abel Demerew Hailu*, Solomon Ahmed Mohammed ${ }^{2}$ and \\ Yohannes Shumet Yimer ${ }^{3}$ \\ 'Department of Pharmacy, Dessie Health Science College, Dessie, Ethiopia \\ ${ }^{2}$ Department of Pharmacy, College of Health Science, Wollo University, Dessie, Ethiopia \\ ${ }^{3}$ Department of Pharmacy, College of Medicine and Health Science, Debre Tabor University, Debre \\ Tabor, Ethiopia
}

Received: 21 October, 2020

Accepted: 07 December, 2020

Published: 09 December, 2020

*Corresponding author: Abel Demerew Hailu, Department of Pharmacy, Dessie Health Science College, Dessie, Ethiopia, Tel: +251920781031.

E-mail: demerewabel@yahoo.com

Keywords: Health-related quality of life; Quality of life; Stroke; Intervention; Patients and in combination

https://www.peertechz.com

Check for updates

\begin{abstract}
Stroke, the leading causes of mortality, disability, and has effects on health-related quality of life. The objective of this review is to review the health-related quality of life of patients with stroke. Relevant kinds of literature were searched from Science Direct, Google Scholar, Hinari, Scopus, Web of Science, PubMed, Cochrane Library, and PROSPERO database using inclusion and exclusion criteria. From 864 searched studies, 20 full-text articles were reviewed. Eighty-five percent ( $\mathrm{n}=17)$ of articles assessed health-related quality of life after the interventions, whereas three (15\%) of studies assessed health-related quality of life before the interventions. In $50 \%$ ( $n=10)$ of studies, physical disability and six (30\%) of studies depression occurred as complications of a stroke. Forty percent $(n=8), 25 \%(n=5), 20 \%(n=4), 20 \%(n=4)$, and $10 \%$ $(n=2)$ of studies medication therapy, physical exercise, psychological intervention, assistive devices, and surgical procedure were utilized as intervention. The occurrences of stroke complications are determinant for poor health-related quality of life and any of the intervention has a strong and positive impact on health-related quality of life. Any of the interventions and assessments provide important information in deciding and implementing appropriate intervention programs.
\end{abstract}

\section{Abbreviations}

HRQOL: Health Related Quality of Life: QOL: Quality of Life

\section{Introduction}

World Health Organization defined stroke as "rapidly developing clinical signs of focal (or global) disturbance of cerebral function, lasting quite 24 hours or resulting in death with no apparent cause other than that of vascular origin" [1]. In every 6 people will have a stroke in life; 15 million people suffer a stroke per year, from these 6 million people die [2]. In developed countries, stroke is a cause for death after cancer and heart condition [3]. In the current situation in Sub-Saharan Africa region stroke cases occur with high morbidity and mortality rate that leads to rapid epidemiological transition [2].

Stroke patients exhibit symptoms like mood changes (depression, apathy), paralysis of an extremity-face, spasticity, loss of memory, contracture pain, and personality changes [1]. Depending on the type and severity, a stroke can leave an individual residual impairment of physical, social, psychological, and cognitive functions [4]. And also features a substantial impact on the psychological well-being of their families [5]. This kind of impacts deteriorate patients perceptions of their position in life concerning their goals, standards, and expectations [6].

Health-Related Quality of Life (HRQOL) is quality of life suffering due to a disease, or health condition, or health care intervention on the individuals' subjective experience in social, psychological, functional, and cognitive processes $[7,8]$. The concept of HRQOL is essential within the assessment of the multiple impacts of a stroke on the patient's life and evaluation of their health states [5]. HRQOL measures encompass physical, 
emotional, social, and subjective feelings of patients and hence, utilized in identifying prioritizing areas, evaluation of the cost-benefit and effectiveness of prophylactic, therapeutic, and rehabilitative interventions [9].

To assess HRQOL, generic and specific measurement tools are developed [10]. Generic HRQOL measurement tools utilized across a wide range of populations and health care interventions, whereas specific HRQOL measurement tools are designed to measure HRQOL only specific subpopulations [11]. Disease-specific HRQOL measurement tools are designed to assess HRQOL of patients with scales and questions that are specific (related) to a disease or health condition [12].

The assessment focuses on the alleviation of symptoms, prevention of deaths, and restoration of patient function. The care of a stroke patient requires measurements of the result, which are critical to assess and evaluate the treatment regimens. Therefore, the objective of this review was to review the HRQOL of patients with stroke.

\section{Material and methods}

\section{Search strategy}

A systematic literature search was conducted from Science Direct, Google Scholar, Hinari, Scopus, Web of Science, PubMed, Cochrane Library, and PROSPERO electronic databases for articles published from January 2000 - July 2020. A manual Google search was utilized to identify some studies and therefore the reference lists of retrieved articles. The entire searches were done July 5-10/2020 using keywords "health-related quality of life", "quality of life", "stroke", "intervention", "patients" and in combination.

\section{Study selection}

Articles were included within the review if they aimed to assess HRQOL of stroke patients. The inclusion criteria were: publication: peer-reviewed and gray literature, type of study: all, population: stroke patients, time: from 2000 to present and language: English. Studies that were published only as dissertations, editorials, opinions, abstracts, and letters to editors were excluded.

\section{Assessment of methodological quality}

Before including the selected articles to the review methodological validity assessment was done and during the review by conducting critical appraisal using preferred reporting items for systematic reviews and meta-analysis (PRISMA) flow diagram and guidance set out by the center for reviews and dissemination [13]. Each of the 20 studies was evaluated for each criterion/question and rated it as "Yes" with score 1 if described partly, we scored it as 0.5 , then o for "No." Then, the entire score was calculated by summing each score and score less than $75 \%$ graded as low quality, $75 \%$ to $90 \%$ graded to moderate quality, and greater than $90 \%$ was graded as high quality.

In this review, three reviewers participated. Two reviewers appraised the full text of each article independently. Any discrepancies between the two reviewers were resolved through discussion with a third reviewer as an arbiter.

\section{Data abstraction}

The author screened the studies based on the inclusion and exclusion criteria. The following details were extracted from each article using an abstraction form: authors, country, sample size, year, study design, HRQOL measurement tool, intervention types, before or after the intervention, HRQOL status, and complications.

\section{Result}

\section{Literature search results}

The searching was conducted through stepwise procedures. The initial advanced search in all databases yields 864 studies. Finally, 20 studies in which full field the inclusion criteria were reviewed. The figure below briefly describes the flow of study selection employed within the study (Figure 1).

\section{Methodological quality of included studies}

The reporting quality results showed that most studies were of high quality $(n=18,75 \%)$, whereas five $(20.9 \%)$ were of moderate quality and one $(4.1 \%)$ were of low quality.

\section{Study characteristics}

All selected studies varied in the study design. The sample size ranged from $24-700$ (Table 1 ).

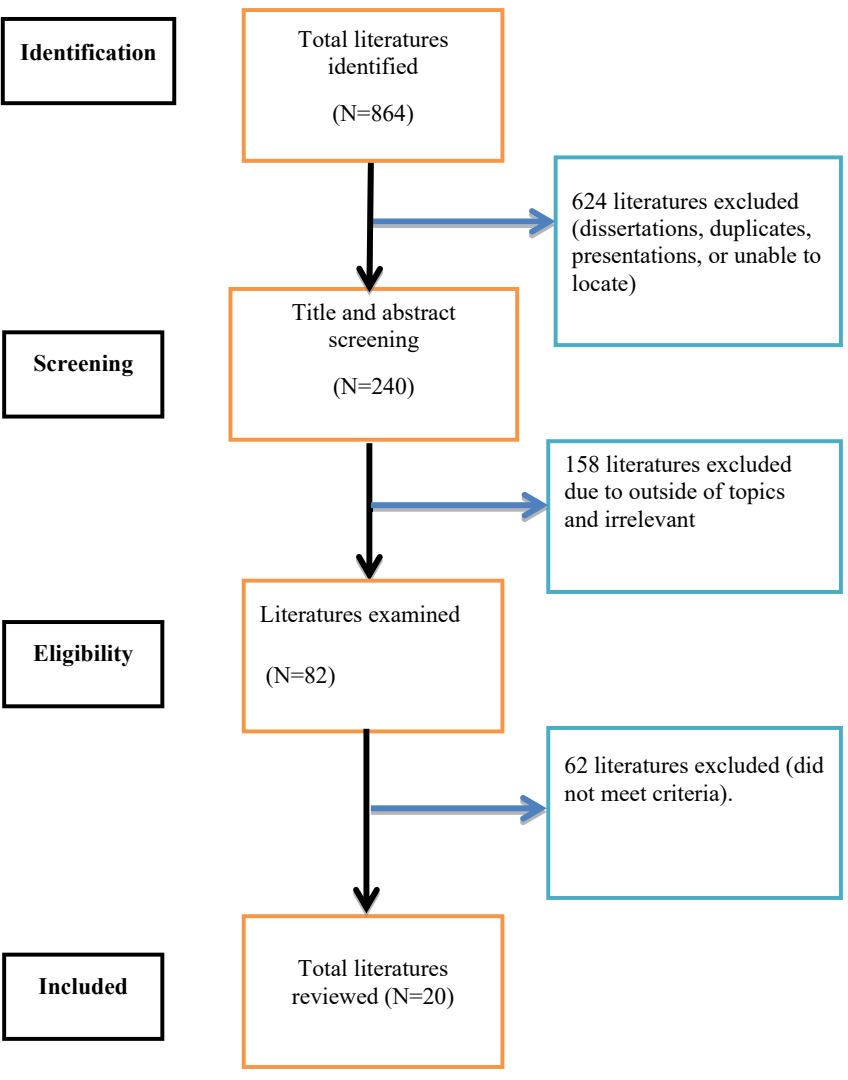

Figure 1: Flow diagram of the study selection. 
Table 1: Study characteristics.

\begin{tabular}{|c|c|c|c|c|c|}
\hline S.n & Author and year & Study design & Sample size & Country & Year \\
\hline 1 & Naess $H$, et al. [15] & Case control & 405 & Norway & 2006 \\
\hline 2 & Carod-Artal J [16] & Cohort study & 118 & Spain & 2000 \\
\hline 3 & Khalid W, et al. [17] & A sequential mix methods approach & 700 & Pakistan & 2016 \\
\hline 4 & Lindgren I [20] & Prospective population based study & 416 & Sweden & 2007 \\
\hline 5 & Kahn SR [21] & Review & 37 articles & Globally & 2000 \\
\hline 6 & Carod-Artal FJ [25] & Review & 87 articles & Western countries & 2009 \\
\hline 7 & Rønning OM [19] & Prospective study & 550 & Norway & 2008 \\
\hline 8 & Kauhanen M-L, et al. [29] & Cohort study & 85 & Finland & 2000 \\
\hline 9 & Chandrasekhar D, et al. [27] & Prospective interventional study & 128 & India & 2018 \\
\hline 10 & Hohmann C [28] & Longitudinal study & 255 & Germany & 2010 \\
\hline 11 & Van Middelaar T, et al. [30] & Retrospective cohort study & 25 & Netherlands & 2015 \\
\hline 12 & Abelha FJ [31] & Longitudinal study & 63 & Portugal & 2008 \\
\hline 13 & Wu D-Y, et al. [32] & Prospective cohort study & 120 & China & 2012 \\
\hline 14 & Holmgren E [33] & $\begin{array}{l}\text { Randomized controlled } \\
\text { trial }\end{array}$ & 34 & Sweden & 2010 \\
\hline 15 & Rand D, et al. [35] & $\begin{array}{l}\text { Study by using Actual accelerometer on each hip for } 3 \text { consecutive days at } \\
\text { home }\end{array}$ & 40 & USA & 2010 \\
\hline 16 & Gosman-Hedström G [36] & Longitudinal randomized trial & 249 & Sweden & 2002 \\
\hline 17 & Clarke P [37] & A secondary analysis & 339 & Canada & 2002 \\
\hline 18 & Thomas LH [38] & A cluster randomized controlled feasibility trial & 413 & England and Wales & 2014 \\
\hline 19 & Kahn SR [22] & Prospective study & 43 & Montreal & 2002 \\
\hline 20 & Armstrong JR [23] & Review & 59 articles & USA & 2011 \\
\hline
\end{tabular}

\section{HRQOL measurement tools}

Fifty percent $(\mathrm{n}=10)$ of articles included in the review ShortForm (SF-36) was utilized to assess HRQOL stroke patients. Whereas, $20 \%(n=4)$ of studies Barthel Index and three (15\%) of studies Stroke Specific Quality of life (QOL) Scale were used to assess HRQOL of stroke patients (Table 2).

\section{Assessment of HRQOL before and after intervention}

Eighty-five percent $(n=17)$ of reviewed articles assessed HRQOL of stroke patients after the interventions of the disease, whereas three $(15 \%)$ of studies assessed HRQOL before the interventions done to the complications of the diseases. In the current review, in fifty percent $(n=10)$ of studies physical disability and in six (30\%) of studies depression occurred the complications of stroke (Table 3 ).

\section{Intervention types and HRQOL Status}

From the reviewed articles, 40\% ( $n=8), 25 \%(n=5), 20 \%$ $(\mathrm{n}=4), 20 \%(\mathrm{n}=4)$, and $10 \%(\mathrm{n}=2)$ of studies medication therapy, physical exercise, psychological intervention, assistive devices, and surgical procedure were utilized as an intervention to overcome the complications of a stroke. Fifty percent $(n=10)$ of studies assessed HRQOL improvement in stroke patients, from this physical and psychosocial well-being of stroke patients were identified as predictors of HRQOL (Table 4).

\section{Discussion}

\section{HRQOL of stroke patients before intervention}

The impact of stroke on HRQOL is disastrous without getting intervention and stroke can complicate multiple domains of life. In the current review, the physical disability problem was assessed in fifty percent of studies $(n=10)$, and in six studies (30\%) reviewed articles depression was occur the complications of a stroke. This was similar to Robinson RG (2006) and Gurenlian J (2002) studies revealed that the brain affected by stroke [14]. Also, HRQOL was significantly reduced with the presence of depression and previous stroke were all significantly associated with worse QOL $(\mathrm{P}=0.0001)$ study done by Pinkney JA (2017) [15]. Brain edema, depression, and emotional problem were the common central nervous system complication of stroke.

Naess H, (2006) study revealed that a close association between low HRQOL and depression among older patients with stroke [16]. Similar studies by Carod-Artal J (2000), Khalid W (2016), and Chaves DBR (2013) described that stroke survivors mostly depressed and their HRQOL was profoundly influenced by increased physical functional dependency, neurologic pain, and depression [17-19]. Also, study conducted by Chen $\mathrm{Q}$ et al. (2019) patients with strokes scored significantly lower in all mental dimensions including vitality, social functioning, role limitations due to emotional problems, and mental health $(\mathrm{P}<.001)[20]$. Brain injuries caused by a stroke can also determine writing and verbal language skills. That, in turn, can produce communication difficulties, causing social isolation, which aggravates depression and thus interferes with HRQOL.

Physical disability is a consistent determinant of HRQOL in stroke survivors in almost all studies and survivors after stroke has very poor HRQOL in the long term after stroke 
[21]. In the present review physical disabilities, shoulder pain, post-thrombotic syndrome (leg pain, edema, deep venous thrombosis, ulceration, and lack of exercise were the most commonly reported complications. This result in line with a study conducted by Lindgren I (2007) revealed that almost one-third of stroke patients develop a physical problem after stroke onset with moderate to severe pain [22] and highest scores were found in the physical and physical functioning domains, with a value of 0.722 with a study done by Sabogal YR (2016) [23]. Also similar to Kahn SR (2000) stated that deep venous thrombosis and blood clots occur in $20 \%$ to $50 \%$ of patients within the first 2 years after the acute thrombotic episode [24]. Patients with deep venous thrombosis in whom post-thrombotic syndrome develops had shown that HRQOL worsens with the severity of post-thrombotic syndrome [25].

Pneumonia is another complication to the present review, which causes breathing and swallowing problems. According to Armstrong JR (2011), pneumonia causes the highest attributable mortality of all medical complications following a stroke. In $6 \%$ of patients suffering from ischemic stroke and $30 \%$ of patients with a hemorrhagic stroke risk to respiratory failure, this leads to intubation [26].

In the current review urinary incontinence also the complications occur after the occurrence of stroke that may

\begin{tabular}{|c|c|}
\hline \multicolumn{2}{|c|}{ Table 2: HRQOL measurement tools } \\
\hline S.n & Author \\
\hline 1 & Naess H, et al. [15] \\
\hline 2 & Carod-Artal J [16] \\
\hline 3 & Khalid W, et al. [17] \\
\hline 4 & Lindgren I [20] \\
\hline 5 & Kahn SR [21] \\
\hline 6 & Carod-Artal FJ [25] \\
\hline 7 & Rønning OM [19] \\
\hline 8 & Kauhanen M-L, et al. [29] \\
\hline 9 & Chandrasekhar D, et \\
\hline 14 & al. [27] \\
\hline 10 & Hohmann C [28] \\
\hline 11 & $\begin{array}{c}\text { Van Middelaar T, et al. } \\
\text { [30] }\end{array}$ \\
\hline 12 & Abelha FJ [31] \\
\hline 15 & Wu D-Y, et al. [32] \\
\hline 14 Holmgren E [33]
\end{tabular}

16 Gosman-Hedström G

[36]

$17 \quad$ Clarke P [37]

18 Thomas LH [38]

$19 \quad$ Kahn SR [22]

$20 \quad$ Armstrong JR [23]
HRQOL measurement tools

Short-Form (SF-36)

Hamilton Rating Scale, Sickness Impact Profile Short Form 36, Frenchay Index, Barthel Index, Rankin Scale, and Scandinavian Stroke Scale Stroke Specific QOL Scale

National Institutes of Health Stroke Scale score and Barthel Index Visual analog scale VEINES QOL questioners

Stroke Impact Scale, Stroke-Specific QOL Scale Short form SF-36

RAND 36- item health survey, Scandinavian, Stroke Scale, and Barthel index

Short form SF-36

Short form SF-36and Barthel index

Short form SF-36

Short form SF-36 and Lawton Instrumental Activities of ADL Scale

SCL-90 and Euro stroke scales (ESS)

Geriatric Depression Scale-15 (GDS-15), Short Form-36 (SF-36)

Physical ability Scale for Individuals with Physical Disabilities (PASIPD) and Short Form-36 (SF-36)

Short Form-36 (SF-36)

Activities of daily living scale (ADL)

Incontinence QOL Instrument (IQoL)

VEINES QOL and Short form SF-36

Clinical Pulmonary Infection Score
Table 3: Assessment of HRQOL before and after intervention $(n=20)$.

\begin{tabular}{|c|c|c|c|}
\hline S.n & Author & \begin{tabular}{|c|} 
HRQOL \\
assessed before \\
/after
\end{tabular} & Complications \\
\hline 1 & Naess $\mathrm{H}$, et al. [15] & After & Depression and physical functioning \\
\hline 2 & Carod-Artal J [16] & Before & Depression and disability \\
\hline 3 & Khalid W, et al. [17] & After & Depression and other complications \\
\hline 4 & Lindgren I [20] & After & Physical functioning (Shoulder pain) \\
\hline 5 & Kahn SR [21] & After & $\begin{array}{l}\text { Deep venous thrombosis, pain, and } \\
\text { leg swelling }\end{array}$ \\
\hline 6 & Carod-Artal FJ [25] & Before & Complications of stroke \\
\hline 7 & Rønning OM [19] & After & Physical and emotional problem \\
\hline 8 & $\begin{array}{l}\text { Kauhanen } M-L \text {, et } \\
\text { al. [29] }\end{array}$ & After & $\begin{array}{l}\text { Physical functioning problem and } \\
\text { depression }\end{array}$ \\
\hline 9 & $\begin{array}{l}\text { Chandrasekhar D, } \\
\text { et al. [27] }\end{array}$ & After & Complications of stroke \\
\hline 10 & Hohmann C [28] & After & Complications of stroke \\
\hline 11 & $\begin{array}{l}\text { Van Middelaar T, } \\
\text { et al. [30] }\end{array}$ & After & CNS problem(brain edema) \\
\hline 12 & Abelha FJ [31] & After & Stroke complication(artery blockage ) \\
\hline 13 & Wu D-Y, et al. [32] & After & $\begin{array}{c}\text { Mental health, stress and limb } \\
\text { movement }\end{array}$ \\
\hline 14 & Holmgren E [33] & After & depression and Physical problem \\
\hline 15 & Rand D, et al. [35] & After & Physical disability \\
\hline 16 & $\begin{array}{c}\text { Gosman-Hedström } \\
\text { G [36] }\end{array}$ & After & Physical disability \\
\hline 17 & Clarke P [37] & After & Wellbeing after stroke \\
\hline 18 & Thomas LH [38] & After & Urinary incontinence \\
\hline 19 & Kahn SR [22] & Before & $\begin{array}{l}\text { Post thrombotic syndrome(leg pain } \\
\text {,edema, deep venous thrombosis, } \\
\text { ulceration) }\end{array}$ \\
\hline 20 & Armstrong JR [23] & After & Pneumonia \\
\hline
\end{tabular}

cause loss of sexual function, social isolation, psychosocial well-being, and QOL [27]. A study conducted by Carod-Artal FJ (2009) reported that sexual dissatisfaction and dysfunction are common in both male and female stroke patients with significant impact on sexual functioning and HRQOL [28].

\section{HRQOL of stroke patients after intervention}

An intervention done in stroke care improves HRQOL of patients and clinicians intending to improve clinical practice or the organization of care. Figure 2 describes types of interventions to overcome complications of stroke according to the taxonomy developed by Lamb (2011) [29].

From the reviewed articles, $40 \% \quad(n=8)$ of studies medication therapy targeted to specific classes of drugs and drugs for other comorbid conditions can be prescribed to combat complications. The responsible provision of drug therapy for achieving the desired improving HRQOL in patients with stroke had been shown effective by Chandrasekhar D [30] and Hohmann, et al. study [31]. Pharmaceutical care provided by the health professionals improving HRQOL in patients with stroke. Treating depression improving HRQOL outcomes and better prognosis achieved where an early diagnosis was made. According to Kauhanen M-L, et al. (2000) study, treating 
Table 4: Intervention types and HRQOL status $(n=20)$.

\begin{tabular}{|c|c|c|c|}
\hline S.n & Author & Intervention types & HRQOL Status \\
\hline 1 & Naess $\mathrm{H}$, et al. [15] & Medication & Improve HRQOL regard to physical functioning \\
\hline 2 & Carod-Artal J [16] & Physical exercise & Functional status and depression were identified as predictors of QOL. \\
\hline 3 & Khalid W, et al. [17] & Psychological intervention at home level & $\begin{array}{c}\text { QOL of Stroke survivors was better than compared to those reported from comparative } \\
\text { settings }\end{array}$ \\
\hline 4 & Lindgren I [20] & Physical exercise, supportive devices & Shoulder pain restricts patients' daily life after stroke \\
\hline 5 & Kahn SR [21] & $\begin{array}{l}\text { Comprehensive medication therapy and } \\
\text { stocking }\end{array}$ & $\begin{array}{l}\text { Identifying predictors of poor } \\
\text { Outcome }\end{array}$ \\
\hline 6 & Carod-Artal FJ [25] & Medical intervention & $\begin{array}{l}\text { Physical and psychosocial } \\
\text { well-being is greatly affected in stroke survivors }\end{array}$ \\
\hline 7 & Rønning OM [19] & Medication therapy & Improvement in HRQoL from 1 to 6 months after stroke \\
\hline 8 & Kauhanen M-L, et al. [29] & Physical and medication therapy & $\begin{array}{l}\text { The most important determinants of } \\
\text { low QOL seem to be depression and being married }\end{array}$ \\
\hline 9 & Chandrasekhar D, et al. [27] & Pharmaceutical care & Pharmaceutical care improve HRQOL of patients \\
\hline 10 & Hohmann C [28] & $\begin{array}{l}\text { Pharmaceutical intervention on drug } \\
\text { therapy }\end{array}$ & $\begin{array}{l}\text { Intensified education and care of patients after ischemic stroke by } \\
\text { dedicated pharmacists based on a concept of pharmaceutical care may maintain HRQoL } \\
\text { of patients }\end{array}$ \\
\hline 11 & Van Middelaar T, et al. [30] & Surgical procedure & $\begin{array}{l}\text { Mental QOL after surgical decompression for space-occupying MCA infarct is comparable } \\
\text { to that in } \\
\text { the general population, whereas physical QOL is worse }\end{array}$ \\
\hline 12 & Abelha FJ [31] & Surgery & Patients undergoing surgery have improved self-perception of QOL \\
\hline 13 & Wu D-Y, et al. [32] & Psychological intervention & Improve HRQOL of patients \\
\hline 14 & Holmgren E [33] & Physical exercise and education & $\begin{array}{l}\text { High-intensive functional exercises implemented in real-life } \\
\text { situations and education focus on falls and safety aspects } \\
\text { to have a better HRQoL }\end{array}$ \\
\hline 15 & Rand D, et al. [35] & Physical activity & Daily physical activity is associated with better HRQL \\
\hline 16 & Gosman-Hedström G [36] & Assistive devices and technology & $\begin{array}{l}\text { Assistive devices were prescribed at low cost and had a high impact on these elderly } \\
\text { people's daily life after stroke }\end{array}$ \\
\hline 17 & Clarke P [37] & social resources and educations & $\begin{array}{l}\text { Social resources can help to alleviate the subjective burden of this common neurological } \\
\text { condition }\end{array}$ \\
\hline 18 & Thomas LH [38] & Toilet assisting program & The programme has a potential reduction in the odds of specific types of incontinence \\
\hline 19 & Kahn SR [22] & $\begin{array}{l}\text { Medication, exercise and psychological } \\
\text { support }\end{array}$ & Post thrombotic syndrome has a significant impacts on QOL \\
\hline 20 & Armstrong JR [23] & Medication & Improve HRQOL of Patients \\
\hline
\end{tabular}

depression greatly improve HRQOL of patients with ischemic stroke [32].

From the reviewed articles, $10 \%(n=2)$ of studies surgical procedure was utilized as the intervention types to overcome the complications of a stroke. Surgery including pacemaker provision, cataract extraction, and podiatric surgery can help to improve HRQOL. According to van Middelaar T, et al. study, patients who have survived surgical decompression for a space-occupying middle cerebral artery showed a good mental QOL [33]. The effect of carotid endarterectomy on stroke patients demonstrated subtle cognitive changes as revealed by neuropsychological testing [34].

In the current review, 20\% $\quad(n=4)$ psychological intervention was utilized to overcome the complications of a stroke. Psychological interventions like cognitive (behavioral) can be administered either individually or in a group. After the psychological intervention, condition of depression, fear, anxiety, and psychological factors declined significantly in the trial group than in the control group, indicates that early psychological intervention can improve the patients' mental health [35].
In the present review, $40 \% \quad(n=8)$ of studies physical exercise and $20 \%(n=4)$ of studies assistive devices intervention were used to overcome the complications. Holmgren (2010) assessed the effect of exercises and significant improvements were found in favor of the intervention group [36]. Evidence suggested by Chan B (2015) revealed that physical exercises and training conducted during acute rehabilitation of stroke patients improve QOL adjusted by years [37]. Similarly, through physical activity, approximately $70 \%$ of all individuals regain their walking ability post-stroke [38].

Environmental or assistive product technology interventions favor for personal indoor and outdoor mobility, facilitating transportation services, and facilitating health services and systems were important for elderly patient's HRQOL improvements [39].

Knowledge interventions through different routes like written material, videos, lectures, or others could help improving adherence to other interventions. A cross-sectional study done by Clarke P (2002) reported that social support and educational resources moderated the impact of poor functional status [40]. 


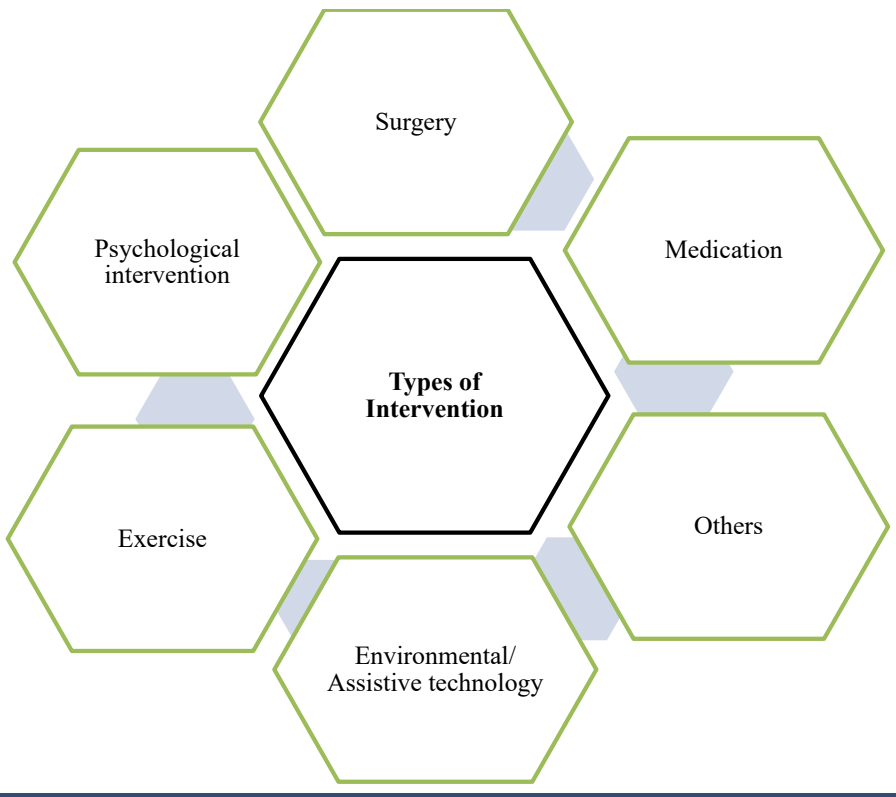

Figure 2: Types of interventions for stroke patients.

The toileting assistance intervention had benefit individuals who are functionally or cognitively impaired and who rely on a career to assist them to maintain continence [41]. Individuals who use bladder-protection pads, behavioral interventions, and bladder training assist to manage incontinence improve HRQOL of the patients [42].

\section{Limitations of this review}

Numerous tools are available to measure HRQOL of stroke patients and every of the reviewed articles uses the distinct tool. This diversity of domains within the assessment of HRQOL makes compression troublesome and it's unclear to conclude that interventions have a sound improvement in HRQOL.

\section{Conclusions}

This review covered wide range of HRQOL measurement tools that has been conducted in patients with stroke. There is no existing measurement tools comprehensively covers all relevant domains or addresses fully the issues of obtaining and combining HRQOL assessment in stroke patients.

The incidence of complications like depression, disability, seizure, and different complications was the determinant of poor HRQOL. Generally, physical functions and psychosocial well-being are greatly affected when the incidence of a stroke.

Inpatient interventional program contains a sturdy and positive impact on HRQOL. Interventions like medication, physical, psychological interventions, and environmental helpful technology have shown effectiveness in HRQOL patients with stroke. The investigation of relevant factors with health-related quality and assessments of individual HRQOL provides necessary data for clinicians and decision-makers to choose upon acceptable treatments and allocation of resources.

\section{Data availability}

The datasets are available from the corresponding author upon reasonable request.

\section{Acknowledgments}

The authors would like to acknowledge Wollo University and Dessie Health Sciences College.

\section{References}

1. Birtane M, Taştekin N (2010) Quality of Life after stroke. Balkan Medical Journal 63-68. Link: https://bit.ly/39LSkgo

2. Canuto MÂdO, Nogueira LT, Araújo TMEd (2016) Health-related quality of life after stroke. Acta Paulista de Enfermagem 29: 245-252.

3. Haacke C, Althaus A, Spottke A, Siebert U, Back T, et al. (2006) Long-term outcome after stroke: evaluating health-related quality of life using utility measurements. Stroke 37: 193-198. Link: https://bit.ly/39QsCHM

4. Sriram S, Asokan K, Thomas TS (2015) Study on the Health Related Quality of Life of Patients with Ischemic stroke. IOSR Journal of Pharmacy and Biological Sciences Ver III 10: 2319-7676.

5. Owolabi M, Ogunniyi A (2009) Profile of health-related quality of life in Nigerian stroke survivors. Eur J Neurol 16: 54-62. Link: https://bit.ly/2JXOVIs

6. Abubakar S, Isezuo S (2012) Health related quality of life of stroke survivors: experience of a stroke unit. Int J Biomed Sci 8: 183-187. Link: https://bit.ly/2K1GeEQ

7. Seidl EMF, da Costa Zannon CML (2004) Qualidade de vida e saúde\&58 aspectos conceituais e metodológicos Quality of life and health\&58; conceptual and methodological issues. Cad Saude Publica 20: 580-588. Link: https://bit.ly/3907r92

8. Hsieh FI, Chiou HY (2014) Stroke: morbidity, risk factors, and care in taiwan. $J$ Stroke 16: 59-64. Link: https://bit.ly/3mShayS

9. Salter KL, Moses MB, Foley NC, Teasell RW (2008) Health-related quality of life after stroke: what are we measuring? Int J Rehabil Res 31: 111-117. Link: https://bit.ly/3IRORRB

10. Sturm JW, Donnan GA, Dewey HM, Macdonell RA, Gilligan AK, et al. (2004) Quality of life after stroke: the North East Melbourne stroke incidence study (NEMESIS). Stroke 35: 2340-2345. Link: https://bit.ly/36SDrXT

11. Coons SJ, Rao S, Keininger DL, Hays RD (2000) A comparative review of generic quality-of-life instruments. Pharmacoeconomics 17: 13-35. Link: https://bit.ly/3qD4huH

12. Zhang Y, Liu B, Liu Z, Wang Y, Zhao H, et al. (2012) Development of a diseasespecific health-related quality of life questionnaire for patients with poststroke spasticity. J Tradit Chin Med 32: 674-678. Link: https://bit.ly/3mTEjRI

13. Centre for Reviews and Dissemination (2009) Systematic reviews: CRD's guidance for undertaking reviews in health care: Centre for Review and Dissemination. York: University of York.

14. Robinson RG (2006) The clinical neuropsychiatry of stroke: Cognitive, behavioral and emotional disorders following vascular brain injury: Cambridge University Press. Link: https://bit.ly/37InDG5

15. Pinkney JA, Gayle F, Mitchell-Fearon K, Mullings J (2017) Health-related quality of life in stroke survivors at the university hospital of the west indies. Journal of Neurology Research 7: 46-58. Link: https://bit.ly/2VNDEFu

16. Naess H, Waje-Andreassen U, Thomassen L, Nyland H, Myhr KM (2006) Health-related quality of life among young adults with ischemic stroke on longterm follow-up. Stroke 37: 1232-1236. Link: https://bit.ly/3gmjCLB

17. Carod-Artal J, Egido JA, González JL, De Seijas EV (2000) Quality of life among stroke survivors evaluated 1 year after stroke: experience of a stroke unit Stroke 31: 2995-3000. Link: https://bit.ly/39P5FV6 
18. Khalid W, Rozi S, Ali TS, Azam I, Mullen MT, et al. (2016) Quality of life after stroke in Pakistan. BMC Neurol 16: 250. Link: https://bit.ly/37F0DrH

19. Chaves DBR, de Sousa Costa AG, de Oliveira ARS, da Silva VM, de Araujo TL, et al. (2013) Comunicação verbal prejudicada-investigação no período pósacidente vascular encefálico. Revista da Rede de Enfermagem do Nordeste 14: 877-885. Link: https://bit.ly/3mVmcKX

20. Chen Q, Cao C, Gong L, Zhang Y (2019) Health related quality of life in stroke patients and risk factors associated with patients for return to work. Medicine 98. Link: https://bit.ly/36QduYQ

21. Rønning OM, Stavem K (2008) Determinants of change in quality of life from 1 to 6 months following acute stroke. Cerebrovasc Dis 25: 67-73. Link: https://bit.ly/36RP2X3

22. Lindgren I, Jönsson AC, Norrving B, Lindgren A (2007) Shoulder pain afte stroke: a prospective population-based study. Stroke 38: 343-348. Link: https://bit.ly/39MMxaf

23. Sabogal YR, Vidal JP, Pedraza RS, Sánchez-Pedreño FO, Guevara MC (2016) Health-related quality of life in stroke patients questionnaire, short version (HRQOLISP-40): validation for its use in Colombia. BMC Neurol 16: 246. Link: https://bit.ly/2Jz24QA

24. Kahn SR, Solymoss S, Lamping DL, Abenhaim L (2000) Long-term outcomes after deep vein thrombosis: postphlebitic syndrome and quality of life. J Gen Intern Med 15: 425-429. Link: https://bit.ly/2JLrzOp

25. Kahn SR, Hirsch A, Shrier I (2002) Effect of postthrombotic syndrome on health-related quality of life after deep venous thrombosis. Arch Intern Med 162: 1144-1148. Link: https://bit.ly/3ql9lyf

26. Armstrong JR, Mosher BD (2011) Aspiration pneumonia afte stroke: intervention and prevention. Neurohospitalist 1: 85-93. Link: https://bit.ly/2VP1h04

27. Nilsson C, Palva K, Rezapour M, Falconer C (2008) Eleven years prospective follow-up of the tension-free vaginal tape procedure for treatment of stress urinary incontinence. Int Urogynecol J Pelvic Floor Dysfunct 19: 1043-1047. Link: https://bit.ly/2L7buTy

28. Carod-Artal FJ, Egido JA (2009) Quality of life after stroke: the importance of a good recovery. Cerebrovasc Dis 27: 204-214. Link: https://bit.ly/3gkIEfO

29. Lamb SE, Becker C, Gillespie LD, Smith JL, Finnegan S, et al. (2011) Reporting of complex interventions in clinical trials: development of a taxonomy to classify and describe fall-prevention interventions. Trials 12: 125. Link: https://bit.ly/33Qajye

30. Chandrasekhar D, Pradeep A, Geoji AS, George AE, Athira V (2018) Impact of intensified pharmaceutical care on health related quality of life in patients with stroke in a tertiary care hospital. Clinical Epidemiology and Global Health 6 : 198-202. Link: https://bit.ly/3qtV3kq

31. Hohmann C, Radziwill R, Klotz JM, Jacobs AH (2010) Health-related quality of life after ischemic stroke: the impact of pharmaceutical interventions on drug therapy (pharmaceutical care concept). Health Qual Life Outcomes 8: 59. Link: https://bit.ly/3giQRzk

32. Kauhanen $\mathrm{ML}$, Korpelainen JT, Hiltunen $\mathrm{P}$, Nieminen $\mathrm{P}$, Sotaniemi KA, et al (2000) Domains and determinants of quality of life after stroke caused by brain infarction. Arch Phys Med Rehabil 81: 1541-1546. Link: https://bit.ly/2VMfn2

33. van Middelaar T, Richard E, van der Worp HB, van den Munckhof $P$, Nieuwkerk PT, et al. (2015) Quality of life after surgical decompression for a spaceoccupying middle cerebral artery infarct: A cohort study. BMC Neurology 15 156. Link: https://bit.ly/3mVxbEm
34. Abelha FJ, Quevedo S, Barros H (2008) Quality of life after carotid endarterectomy. BMC Cardiovascular Disorders 8: 33. Link: https://bit.ly/2JzGdIN

35. Wu DY, Guo M, Gao YS, Kang YH, Guo JC, et al. (2012) Clinical effects of comprehensive therapy of early psychological intervention and rehabilitation training on neurological rehabilitation of patients with acute stroke. Asian Pac J Trop Med 5: 914-916. Link: https://bit.ly/37WQYNt

36. Holmgren E, Gosman-Hedström G, Lindström B, Wester P (2010) What is the benefit of a high-intensive exercise program on health-related quality of life and depression after stroke? A randomized controlled trial. Adv Physiother 12 125-133. Link: https://bit.ly/37Jp8Uy

37. Chan B (2015) Effect of increased intensity of physiotherapy on patient outcomes after stroke: An economic literature review and cost-effectiveness analysis. Ont Health Technol Assess Ser 15: 1-43. Link: https://bit.ly/2L4tyh5

38. Rand D, Eng JJ, Tang PF, Hung C, Jeng JS (2010) Daily physical activity and its contribution to the health-related quality of life of ambulatory individuals with chronic stroke. Health Qual Life Outcomes 8: 80. Link: https://bit.ly/3qD0Y6I

39. Gosman-Hedström G, Claesson L, Blomstrand C (2002) Assistive devices in elderly people after stroke: a longitudinal, randomized study-The Göteborg $70+$ stroke study. Scandinavian Journal of Occupational Therapy 9: 109-118 Link: https://bit.ly/36QKiAX

40. Clarke P, Marshall V, Black SE, Colantonio A (2002) Well-being after stroke in Canadian seniors: findings from the Canadian Study of Health and Aging. Stroke 33: 1016-1021. Link: https://bit.ly/33RCxsG

41. Thomas LH, Watkins CL, Sutton CJ, Forshaw D, Leathley MJ, et al. (2014) Identifying continence options after stroke (ICONS): a cluster randomised controlled feasibility trial. Trials 15: 509. Link: https://bit.ly/3otCaML

42. Ko Y, Lin SJ, Salmon JW, Bron MS (2005) The impact of urinary incontinence on quality of life of the elderly. Am J Manag Care 11: S103- S111. Link: https://bit.ly/3glzl89

\section{Discover a bigger Impact and Visibility of your article publication with}

\section{Peertechz Publications}

\section{Highlights}

* Signatory publisher of ORCID

* Signatory Publisher of DORA (San Francisco Declaration on Research Assessment)

- Articles archived in worlds' renowned service providers such as Portico, CNKI, AGRIS, TDNet, Base (Bielefeld University Library), CrossRef, Scilit, J-Gate etc.

* Journals indexed in ICMJE, SHERPA/ROMEO, Google Scholar etc.

* OAI-PMH (Open Archives Initiative Protocol for Metadata Harvesting)

* Dedicated Editorial Board for every journa

* Accurate and rapid peer-review process

* Increased citations of published articles through promotions

* Reduced timeline for article publication

Submit your articles and experience a new surge in publication services (https://www.peertechz.com/submission).

Peertechz journals wishes everlasting success in your every endeavours.

Copyright: @ 2020 Hailu AD, et al. This is an open-access article distributed under the terms of the Creative Commons Attribution License, which permits unrestricted use distribution, and $r$ eproduction in any medium, provided the original author and source are credited.

Citation: Hailu AD, Mohammed SA, Yimer YS (2020) Health-related quality of life of stroke patients before and after intervention: Systematic review. J Biol Med 4(1): 022-028. DOI: https://dx.doi.org/10.17352/jbm.000023 